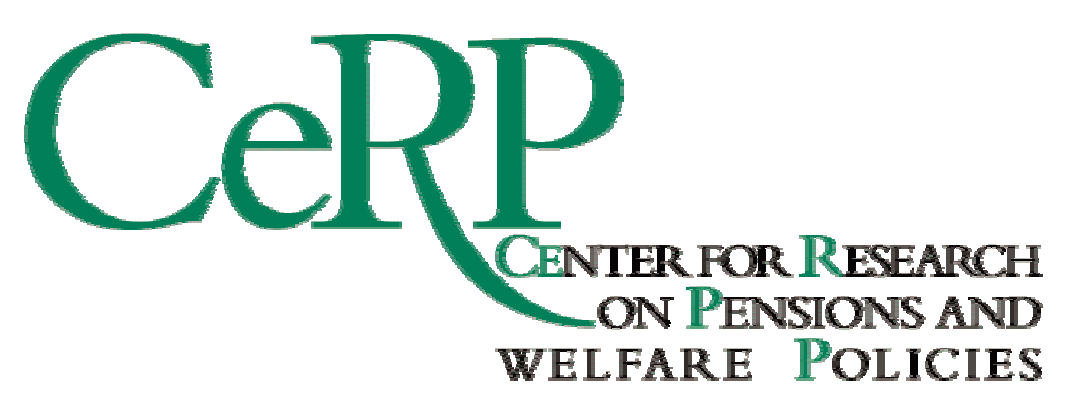

Working Paper 14/01

INVESTOR ACTIVISM AND FINANCIAL MARKET STRUCTURE

Thomas H. Noe

\footnotetext{
- A.B. Freeman School of Business, Tulane University phone: $504-8655425$

Research Department, Federal Reserve Bank of Atlanta

e.mail: tnoe@mailhost.tcs.tulane.edu
}

This paper was presented at the CEPR/CeRP/ESF/FEEM/Fondazione Courmayeur-CNPDS Conference "The Firm and Its Stakeholders: the Evolving Role of Corporate Finance" , Courmayeur, March 22-23. 


\section{Investor activism and financial market structure}

\section{by Thomas H. Noe}

A. B. Freeman School of Business, Tulane University, New Orleans, LA 70118-5669, phone: (504) 865-5425, e-mail:

tnoe@mailhost.tcs.tulane.edu.

First draft: September 18, 1997. This draft: November 15, 2001.

Summary. This article investigates investor activism when a number of investors are capable of expending resources to exercise a role in corporate governance. Strategic investors make monitoring decisions and trade in anonymous financial markets with other agents whose trades are motivated by liquidity considerations. In this setting, a core group of monitoring investors emerges endogenously to curtail managerial opportunism. These core activist investors pursue activist policies and engage in heavy trading on both the buy and the sell sides of the market. In addition, a fringe group of monitoring investors, who are somewhat active and trade only on the buy side, may emerge. Although the smallest investors are passive, there is no monotonic relationship between shareholdings and activism. In fact, among those investors who choose to monitor with positive probability, those with smaller holdings are the most active. In addition to characterizing the emergence of monitoring activity in the presence of numerous potential activist investors, we also develop some comparative statics. Some of these comparative statics are counterintuitive from the perspective of models that fail to endogenize both security market structure and investor activism. For example, it is shown that increasing the size of the shareholdings controlled by informed, strategic investors may reduce bid-ask spreads.

I would like to thank seminar participants at 1999 European Finance Meetings, Carnegie Mellon University, the University of Pittsburgh, Rice, the University of Texas, and the University of Texas at Dallas for helpful comments. I am also especially grateful to Laura Starks, Ernst Maug, and an anonymous referee, and the editor, Michael Fishman, for detailed comments on earlier drafts of this paper. The usual disclaimer applies. 


\section{Investor activism and financial market structure}

\section{Introduction}

The right to govern corporations rests formally with shareholders. However, the effective exercise of this formal right is fraught with difficulties. Shareholders typically lack intimate knowledge of the firm's management or line(s) of business. Those investors who possess the general skills required for effective corporate monitoring must still expend resources gathering the firm-specific information required to monitor management. The costs of these investments in corporate governance are borne by the investor undertaking the monitoring. However, the benefits of increased vigilance accrue to all shareholders. Internalizing the gains from monitoring via increasing holdings is difficult because passive security owners will not sell to a monitoring investor without impounding the expected gains from monitoring activity into the securities' price. In addition, a number of legal restrictions also discourage investors from acquiring substantial ownership positions in individual firms. ${ }^{1}$

This discussion seems to indicate that monitoring, if performed at all, is performed by a single, large outside shareholder. A number of researchers have analyzed shareholder activism in the governance process under these conditions. ${ }^{2}$ However, a single, large outside shareholder monopolizing monitoring is not the only pattern of shareholder intervention in modern corporations. Active monitoring by numerous moderate-size blockholders is commonplace and is receiving growing attention in the finance literature. Many institutional investors believe that they can profit from following "relationship" investment strategies which involve first making a substantial investment in a firm and then intervening to monitor its management (Chernoff and Star, 1993). In fact, some investors such as Warren Buffet,

1 Section 16(b) of the 1934 Securities Act limits the ability of investors to sell after the investor or the "group" to which the investor belongs attains a 10\% share of the firm's stock. The definition of group is vague. The prudent-man rule adopted by ERISA establishes legal liability standards that discourage some institutions from taking large stakes and engaging in aggressive monitoring (Hawley and Williams, 1996).

2 See, for example, Shleifer and Vishny (1986), Admati, Pfleiderer, and Zechner (1994), Kahn and Winton (1998), and Maug (1998). 
LENS, and Bennet LeBow specialize in strategic or "relationship" investment strategiesbuying blocks of shares in companies with the anticipation of later profiting by improving their performance. For example, the LENS fund's investment strategy has been described by some commentators as "investing in a handful of poor performers and then relentlessly pestering their managers to adopt a better strategy" (Economist, 1997). Intervention through such block share purchases has been shown to improve corporate performance (Bethel, Liebeskind, and Opler (1998)). Other investors, primarily institutions, although they do not deliberately buy underperforming firms with a view to improving management, believe that they can create value both for themselves and for the companies they invest in through a policy of intense monitoring combined with selective intervention in exceptional cases (CalPERS, 1998). The evidence supporting the value of this sort of monitoring is mixed (Opler and Sokobin (1998) and Gillan (1995)). Nevertheless, institutions do pursue activist policies and, as Parino, Sias, and Starks (2000) document, they also trade actively during periods of governance upheaval.

The aim of this article is to explain why, despite the obstacles of shareholder intervention discussed previously, these intervention strategies are viable. We focus on the case of monitoring by investors who, when they purchase shares, aim to profit by intervention. Thus, we are not concerned with situations in which monitoring occurs because of a large, initial-ownership position acquired for reasons unrelated to relationship investing, such as monitoring by a family trust owned by the descendants of a firms's founder. For this reason, we assume that, before they trade, no investor initially owns a large enough fraction of the firm to motivate monitoring. Thus, profits from newly acquired shares are required to justify the costs of monitoring. Our analysis (starting in Section 2) models a publicly traded firm whose shares are widely traded in an active secondary market. Some investors, whom we term "strategic investors," are able to engage in costly monitoring of the firm's management. This monitoring thwarts managerial resource diversion. These strategic investors 
can trade in both riskless bonds and equity claims on the firm's output. Simultaneous with their trading decision, strategic investors decide whether to monitor management. Other, nonstrategic investors may also trade. However, nonstrategic investors are not able to monitor managers and are motivated to trade because of liquidity considerations. All investors trade with competitive, risk-neutral marketmakers who post bid-ask quotes.

In Section 3, we analyze this model and demonstrate that, by exploiting private information regarding the correlation between their own trading and monitoring activities, strategic investors are able to capture trading profits sufficient to justify a positive level of monitoring activity. In our model, strategic investors are not endowed with private information. Instead, they produce information through their own actions. For this reason, information production is circumscribed by equilibrium incentive conditions, which require that stochastic monitoring is, ex ante, preferred to deterministic monitoring. This constraint distinguishes our analysis from settings in which private information and uncertainty are exogenous, and this difference has important consequences.

Optimal monitoring strategies call for strategic investors to always buy shares when they monitor. If they choose not to monitor, strategic investors either sell their shares or hold on to their initial stake. Strategic investors with the highest likelihood of monitoring, whom we term "core" monitors, are the most likely to attempt to profit by selling out when they decide not to monitor. Thus, expected selling activity will be positively correlated with expected activism. In this sense, "voice" and "exit" are, ex ante, complementary strategies for investors, not substitutes. Other strategic investors, whom we term "fringe" monitors, will buy when they decide to monitor but are deterred by bid-ask spreads from selling when they decide not to monitor. The smallest shareholders capable of strategic intervention will generally eschew trading and monitoring entirely, opting for passivity. For the smallest investors, the profits from capital appreciation and trading cannot offset monitoring costs, and because they do not monitor they also lack the private information requisite for avoiding 
adverse selection costs in the financial market. However, the activist core monitors will also generally not be the investors with the greatest wealth or the largest initial positions in the firm's stock. In fact, when multiple investors monitor, the investors with the largest initial endowments of shares become the less active fringe monitors. Further, for fringe monitors, activism is inversely proportional to initial share endowment.

This result follows from the equilibrium incentive conditions. In order to trade profitably on monitoring, monitoring must not be anticipated. For monitoring not to be anticipated, a monitoring investor must be willing to forego monitoring at equilibrium prices. The willingness of an investor to forego monitoring depends positively on his conjecture regarding the aggregate level of monitoring by other investors and negatively on the size of his initial stake in the firm. Thus, incentive compatibility requires that high-endowment monitoring investors conjecture higher levels of monitoring by other shareholders than low-endowment monitoring investors. Given that, in equilibrium, conjectures are always correct, this can only be the case if large-endowment investors' equilibrium probabilities of monitoring are smaller than those of other, smaller, monitoring investors. These arguments lead to the following conclusions. Despite the fact that (i) only one investor need monitor and (ii) there are no cost savings or scale economies in monitoring, (1) monitoring efforts may be undertaken by a number of different strategic investors with moderate wealth and shareholdings rather than exclusively by the largest strategic investor, and (2) an investor's activism intensity will not be monotonically related to the size of strategic shareholdings or the overall wealth of the investor. ${ }^{3}$

3 In other modeling contexts it has also been shown that the incentive compatibility conditions for stochastic equilibrium behavior can lead to surprising conclusions. For example, a result produced by Bhattacharya and reported in Spatt (1988) shows that when entry into takeover contests is costly, equilibrium contest-entry strategies are stochastic. Moreover, incentive compatibility conditions for stochastic entry force the entry probability of each individual potential raider to fall rapidly as the number of potential entrants increases. Entry probabilities fall so rapidly that the likelihood of a takeover decreases as the number of potential raiders increases. 
After developing these general results, we analyze specific cases. In the first case, analyzed in Section 4, strategic investors do not have a toehold stake in the firm. In the second case, analyzed in Section 5, the wealth of strategic investors is initially tied up in the firm. In both Sections 4 and 5, a comparative statics analysis is used to relate monitoring effectiveness and bid-ask spreads to the wealth of strategic investors, market depth, and the number of potential strategic monitors. Some of the relationships between corporate and market structure variables that we derive in Sections 4 and 5 may seem counterintuitive from the perspective of either standard microstructure models, in which strategic informed investors are not activists, or from the perspective of corporate governance models that ignore financial market structure. For example, in most microstructure models with exogenous uncertainty, increased ownership by strategic investors, relative to liquidity investors, increases spreads. In fact, Kini and Mian (1993) test this implication of microstructure analysis by relating strategic ownership to bid-ask spreads. However, our analysis in Section 5 shows that increased strategic ownership can either raise or lower spreads. The increased volume of informed trades tends to increase spreads, ceteris paribus, as one should expect. However, there is a countervailing effect: Higher levels of strategic ownership increase optimal levels of monitoring, thus reducing output uncertainty. This effect lowers the profits of strategic investors and thus the spreads that marketmakers charge. Therefore, the rejection of a monotonic relationship between strategic ownership and spreads, as in Kini and Mian's (1993) tests, is not evidence against the importance of strategic trading in shaping financial market structure.

After developing these comparative statics, we consider, in Section 6, the robustness of our results. We argue that our results are not qualitatively dependent on the specific microstructure assumptions made in developing our analysis. In this section we also consider the impact of endogenizing the security demands of liquidity traders, modifying the managerial monitoring technology, incorporating uncertainty regarding monitoring costs, and 
allowing strategic shareholders to target more than one firm for relationship investment. We show that these modifications do not overturn any of our central results.

Finding the exact coordinates of this research within the matrix of theoretical research on market structure, corporate governance, and managerial incentives is difficult. However, its nearest neighbors appear to be Winton (1993), and Cornelli and Li (1999). Like Winton (1993) but in contrast to much of the rest of the literature, more than one shareholder can monitor management. Further, our assumption that monitoring improves performance also tracks Winton (1993). However, in many ways our work is quite distinct from Winton's. First, our analysis integrates corporate governance into a microstructure model that endogenously generates the illiquidity required to induce monitoring. The analysis shows that endogenizing liquidity costs has important consequences. Winton assumes instead that inside owners pay an exogenously specified cost for liquidating their positions. Unlike our paper and Winton (1993), which focus on relationship investing, Cornelli and Li (1999) model strategic share purchases in takeovers by arbitragers. However, as in our paper, in Cornelli and Li, strategic traders profit from trading based on endogenously generated private information. In our model, this information concerns monitoring strategy. In Cornelli and $\mathrm{Li}$, the endogenous information is each arbitrager's knowledge of her own presence in the market. Two key differences exist between our work and that of both Winton and Cornelli and Li. Our agents (a) can operate on both the buy and sell sides of the market and (b) may have heterogenous endowments. In Winton, agents are endowed with ownership stakes, so that their only option is whether to liquidate these stakes or hold and monitor. In Cornelli and Li, agents have no initial ownership stake, so that their option is either to buy or stay out. We endow agents with a mix of shares and liquid financial assets and shares. For this reason, agents can operate on both sides of the market. How buy side activism and sell-side trading are related is, in fact, one key focus of our paper. The other key difference between our work and that of Cornelli and Li and Winton, is that ours allows for agents with 
heterogenous endowments. How these heterogeneous endowments translate into differences in equilibrium monitoring behavior is the other focal issue in our work.

\section{Model}

Consider a two-date economy, with time indexed by $t=0,1$, populated by a set of $\mathcal{N}=\{1,2, \ldots, N\}$ strategic investors, nonstrategic investors, a marketmaker, a firm, and a manager. Strategic investors have the option of monitoring the manager. In addition, they have the option of investing either in a riskless liquid asset or "bond" paying $\$ 1.00$ at date 1 , or in the firm's stock. No short sales of the stock or bond are permitted. The firm is controlled by the manager. It is assumed that in the absence of monitoring by at least one shareholder, managers will be able to transfer firm value to personal consumption. This transfer reduces the value of the firm to 0 . Monitoring by at least one shareholder prevents this diversion of value. Without diversion, each share is worth $\$ 1.00$. Thus, the value of a share is $\$ 1.00$ if one or more shareholders monitor and equal to 0 otherwise. Each strategic investor who monitors pays a fixed cost of $c$ dollars. The assumption that, in order to block perk consumption, only a single shareholder need monitor implies that monitoring only by the largest shareholder is prima facia viable. If instead we assumed that the efforts of many shareholders were required for efficient monitoring, then one of our important later results - that smaller shareholders may share the burden of monitoring in equilibrium with larger shareholders-would be engendered purely by the monitoring technology, even in the absence of financial market effects. Similarly, allowing for different monitoring costs for different investors would also obscure the effect of financial market structure on the equilibrium level of stochastic monitoring.

To initiate the analysis, first consider the optimal portfolio/monitoring decisions of the strategic investors. Let $v_{-i}$ represent strategic investor $i$ 's conjecture regarding the probability that a share will pay out $\$ 1.00$ if $i$ does not monitor. This also equals the expected share value given the zero/one payoff normalization. If investor $i$ holds $\phi_{i}$ shares 
of the firm's stock posttrade, then it is (sub) optimal for $i$ to monitor whenever

$$
\phi_{i}-c>(<) \phi_{i} v_{-i}
$$

At the start of the period, traders have the option of buying or selling shares. Price determination in the securities market is modeled using a standard microstructure approach. At the start of the period, the marketmaker posts an ordered pair of prices, $p=\left(p_{A}, p_{B}\right)$, consisting of an ask price, $p_{A}$, representing the price at which the marketmaker sells, and a bid price, $p_{B}$, representing the price at which the marketmaker buys. Traders, taking these posted prices as given, trade. The relevant budget constraint for the investors is as follows. Each strategic investor starts the period with an endowment of $w_{i}=\left(\phi_{i}^{o}, b_{i}^{o}\right)$, which consists of $\phi_{i}^{o}$ shares and $b_{i}^{o}$ riskless bonds. Strategic investor $i$ then trades to a position consisting of $\phi_{i}$ stocks and $b_{i}$ bonds. Since bond prices and payoffs are fixed at 1 , the total expenditure by an investor for purchasing securities is $\left(b_{i}-b_{i}^{o}\right)^{+}+\left(\phi_{i}-\phi_{i}^{o}\right)^{+} p_{A} \cdot{ }^{4}$ The total funds available for investment equal the proceeds from the sale of the initial stock-and-bond endowment, $\left(b_{i}-b_{i}^{o}\right)^{-}+\left(\phi_{i}-\phi_{i}^{o}\right)^{-} p_{B}$. Total purchases of assets are the sum of bond and stock purchases, $\left(b_{i}-b_{i}^{o}\right)^{+}+\left(\phi_{i}-\phi_{i}^{o}\right)^{+} p_{A}$. The budget-balancing constraint thus implies that

$$
\left(b_{i}-b_{i}^{o}\right)^{+}+\left(\phi_{i}-\phi_{i}^{o}\right)^{+} p_{A}=\left(b_{i}-b_{i}^{o}\right)^{-}+\left(\phi_{i}-\phi_{i}^{o}\right)^{-} p_{B} .
$$

Bondholdings after trade are given by

$$
b_{i}=b_{i}^{o}+\left(\phi_{i}-\phi_{i}^{o}\right)^{-} p_{B}-\left(\phi_{i}-\phi_{i}^{o}\right)^{+} p_{A} .
$$

The smallest possible terminal security holding is 0 and results from a total liquidation of the investors' initial endowment. The largest possible holding for investor $i$, which we represent by $\bar{\phi}\left(p, w_{i}\right) \stackrel{\text { def }}{=} \phi_{i}^{o}+\left(b_{i}^{o} / p_{A}\right)$, results from the investor $i$ investing all of her liquid

\footnotetext{
4 Also note that $(\cdot)^{+}$represents the function $x \rightarrow \max [x, 0]$, and $(\cdot)^{-}$represents the function $x \rightarrow \max [-x, 0]$.
} 
wealth in shares. Since monitoring is a choice variable for the investor, she will choose the monitoring policy that maximizes her payout. Thus, investor $i$ 's payoff is

$$
\operatorname{Max}_{\phi_{i} \in\left[0, \bar{\phi}\left(p, w_{i}\right)\right]}\left(b_{i}^{o}+\left(\phi_{i}-\phi_{i}^{o}\right)^{-} p_{B}-\left(\phi_{i}-\phi_{i}^{o}\right)^{+} p_{A}\right)+\max \left[\phi_{i}-c, \phi_{i} v_{-i}\right]
$$

Viewed as a function of $\phi$, this expression is convex over $\left[0, \phi_{i}^{o}\right]$ and over $\left[\phi_{i}^{o}, \bar{\phi}\left(p, w_{i}\right)\right]$. Thus, it attains its maximum at the extreme points of these two regions. Therefore, the optimal investment share purchase is attained at either 0 , or $\phi_{o}$, or $\bar{\phi}$. In other words, the strategic investor will either liquidate her holding, or stand pat, or augment her holdings to the extent permitted by her wealth. If we restrict attention to these three pure trading strategies, we obtain the following set of possible portfolio positions: $\Phi(p, w)=\left\{0, \phi_{o}, \bar{\phi}(p, w)\right\}$. This analysis indicates that if no strategic investor has liquid wealth and no strategic investor's share endowment exceeds the costs of monitoring, no monitoring can take place. To rule out these uninteresting cases, we assume that

$$
\max _{i} b_{i}^{o}>0 \text { or } \max _{i} \phi_{i}^{o}>c
$$

Next, we specify the governance structure. Let 1 represent the decision to monitor and 0 the decision not to monitor, and let $M=\{1,0\}$, where $M$ represents the monitoring decision of an individual strategic investor. Let $\mathbf{M}=M^{N}$ represent the monitoring decision of all strategic investors. The portfolio-strategy set of an individual investor $i$ given prices $p$ is given by $\Phi_{i}(p) \stackrel{\text { def }}{=} \Phi\left(p, w_{i}\right)$. The vector of all portfolio strategies for all strategic investors is given by $\boldsymbol{\Phi}(p) \stackrel{\text { def }}{=} \prod_{i} \Phi_{i}(p)$. Let $I_{M}^{i}$ represent the indicator function for whether investor $i$ monitors. Let $I_{M}: \mathbf{M} \rightarrow\{0,1\}$ be the indicator function for monitoring, that is, $I_{M}(\mathbf{m})=1$ if at least one investor monitors and 0 otherwise. For each fixed bid-ask price pair, $p$, the utility function for investors is represented by the map $u_{i}(\cdot, p): \mathbf{\Phi}(p) \times \mathbf{M} \rightarrow \mathbb{R}$ given by

$$
u_{i}(\boldsymbol{\phi}, \mathbf{m}, p)=\phi_{i} I_{M}(\mathbf{m})+\left(b_{i}^{o}+\left(\phi_{i}-\phi_{i}^{o}\right)^{-} p_{B}-\left(\phi_{i}-\phi_{i}^{o}\right)^{+} p_{A}\right)-c I_{M}^{i}(\mathbf{m}) .
$$


The strategy space for investor $i, S_{i}(p)$, is $M \times \Phi_{i}(p)$. The pure strategy space for investors is

$$
S(p)=\prod_{i=1}^{N} S_{i}(p) .
$$

The number of shares strategic investors choose to buy is given by the map $d_{B}: \Phi \rightarrow \mathbb{R}^{+}$, where

$$
d_{B}(\phi)=\sum_{i=1}^{N}\left(\phi_{i}-\phi_{o}\right)^{+} .
$$

The demand of strategic investors in dollar terms is given by $D_{B}(\cdot)=p_{A} d_{B}(\cdot)$. Similarly, the number of shares strategic investors choose to sell is given by

$$
d_{S}(\phi)=\sum_{i=1}^{N}\left(\phi_{o}-\phi_{i}\right)^{+} ;
$$

dollar sell-side demand is given by $D_{S}(\cdot)=p_{B} d_{S}(\cdot)$.

Investors and managers are allowed to submit random demands for shares and to monitor randomly. This requires some new definitions. For any set $S$, let $\operatorname{rv}(S)$ represent the set of $S$-valued random variables. Strategic investors choose monitoring strategies defined on $\operatorname{rv}(M)$ and trading strategies defined on $\operatorname{rv}\left(\Phi_{i}\right)$. The underlying probability space is assumed to be rich enough to permit the construction of all joint probability distributions over $\mathbf{\Phi} \times \mathbf{M}$.

\subsection{Nonstrategic investors and price determination}

Strategic investors are not the only investors trading in the firm's shares. Other, nonstrategic liquidity investors also trade the firm's shares for reasons of liquidity. We assume that the level of liquidity trade is exogenous. Let $\tilde{\ell}_{B}(p)\left(\tilde{\ell}_{S}(p)\right)$ represent the number of shares liquidity investors demand to buy (sell). This quantity can be a function of the bid and ask prices, $p=\left(p_{A}, p_{B}\right)$, quoted by the marketmaker.

The marketmaker's profits from the ask market is given by

$$
\mathrm{E}\left[\left(d_{B}(\tilde{\boldsymbol{\phi}})+\tilde{\ell}_{B}(p)\right)\left(p_{A}-I_{M}(\tilde{\mathbf{m}})\right)\right] .
$$


Because marketmakers quote fixed prices independent of order flow, all orders will be placed with the marketmaker who provides the most favorable quotes. Bertrand competition between marketmakers implies that this profit term equals zero. ${ }^{5}$ That is,

$$
\mathrm{E}\left[\left(d_{B}(\tilde{\boldsymbol{\phi}})+\tilde{\ell}_{B}(p)\right)\left(p_{A}-I_{M}(\tilde{\mathbf{m}})\right)\right]=0 .
$$

The same Bertrand condition applied to the bid market ensures that equilibrium marketmaker profit equals zero in this market as well.

$$
\mathrm{E}\left[\left(d_{S}(\tilde{\phi})+\tilde{\ell}_{S}(p)\right)\left(I_{M}(\tilde{\mathbf{m}})-p_{B}\right)\right]=0 .
$$

We impose the following structure on liquidity trader demand. Buy-side liquidity investors demand a random dollar amount, $\tilde{X}_{B}$, in the firm's stock. Thus liquidity investor buy-side demand in terms of shares, $\tilde{\ell}_{B}$, is given as follows:

$$
\ell_{B}(p)=\tilde{X}_{B} / p_{A}
$$

Sell-side liquidity investors sell an exogenously given random number of shares, $\tilde{x}_{S}$; thus, liquidity investor sell-side demand is given as follows:

$$
\ell_{S}(p)=\tilde{x}_{S}
$$

We assume that the random liquidity investor demand parameters, $\tilde{X}_{B}$ and $\tilde{x}_{S}$, are statistically independent of the trading/monitoring strategy of informed shareholders. We let $L_{B}=\mathrm{E}\left[\tilde{X}_{B}\right]$ represent expected buy-side dollar demand and we let $l_{S}=E\left[\tilde{x}_{S}\right]$ represent expected sell-side share demand. Because, as we shall see, only the expected level of liquidity

5 The fixed quote assumption is required for making the inference that Bertrand competition implies zero marketmaker profits. In a Kyle setting, where quotes are responsive to order flow, traders may, in equilibrium, split orders between competing marketmakers even if one market maker offers a more favorable pricing schedule. See Burnhardt and Hughson (1997). 
demand affects asset prices, we will, in the subsequent analysis, refer to expected liquidity demand simply as "liquidity demand." 6

\subsection{Equilibrium}

For pairs of vectors $x, y \in \mathbb{R}^{N}$, let

$$
x={ }_{-i} y \stackrel{\text { def }}{=} x_{j}=y_{j}, \forall j \neq i .
$$

An equilibrium is 3 -tuple, $\left(\tilde{\phi}^{*}, \tilde{\mathbf{m}}^{*}, p^{*}\right)$, consisting of trading strategies $\tilde{\boldsymbol{\phi}}^{*} \in \prod_{i} \operatorname{rv}\left(\Phi_{i}(p)\right)$, monitoring strategies $\tilde{\mathbf{m}}^{*} \in \operatorname{rv}(\mathbf{M})^{N}$, and bid-ask prices $p^{*}=\left(p_{A}^{*}, p_{B}^{*}\right)$. This 3-tuple satisfies the following conditions: (i) The collection $\left\{\left(\tilde{\phi}_{i}^{*}, \tilde{m}_{i}^{*}\right)\right\}_{i}$ are pairwise independent; (ii) The marketmaker breakeven conditions (BEA) and (BEB) are satisfied; and,

(iii) for all $i=1,2 \ldots N$, the following condition holds: $\forall \tilde{\phi} \in \prod_{j} \operatorname{rv}\left(\Phi_{j}(p)\right), \tilde{\mathbf{m}} \in \operatorname{rv}(M)^{N}$ such that $\tilde{\boldsymbol{\phi}}={ }_{-i} \tilde{\boldsymbol{\phi}}^{*}, \tilde{\mathbf{m}}={ }_{-i} \tilde{\mathbf{m}}^{*}$, and $\left(\tilde{\phi}_{i}, \tilde{m}_{i}\right)$ is independent of $\left\{\tilde{\phi}_{j}^{*}, \tilde{m}_{j}^{*}\right\}_{j \neq i}$, is is the case that

$$
\mathrm{E}\left[u_{i}\left(\tilde{\boldsymbol{\phi}}^{*}, \tilde{\mathbf{m}}^{*}, p^{*}\right)\right] \geq \mathrm{E}\left[u_{i}\left(\tilde{\boldsymbol{\phi}}, \tilde{\mathbf{m}}, p^{*}\right)\right] .
$$

\section{General results}

\subsection{Equilibrium bid and ask prices}

For any monitoring strategy vector $\tilde{\mathbf{m}}$, let $v(\tilde{\mathbf{m}})$ represent the value of one share of the firm's stock under $\tilde{\mathbf{m}}$; that is,

$$
v(\tilde{\mathbf{m}})=\mathrm{E}\left[I_{M}(\tilde{\mathbf{m}})\right] .
$$

For any vector $\mathbf{m} \in \mathbf{M}$, let $\left(\left.\mathbf{m}\right|^{-i} n\right)$ represent the vector obtained from $\mathbf{m}$ by replacing the $i$ th component of $\mathbf{m}$ by 0 , the symbol representing the decision not to monitor. Let

$$
v_{-i}(\tilde{\mathbf{m}})=\mathrm{E}\left[I_{M}\left(\left(\left.\tilde{\mathbf{m}}\right|^{-i} 0\right)\right)\right]
$$

6 Assuming that the distribution of nonstrategic demand is fixed in terms of numbers of shares and buy-side demand is fixed in dollar terms simplifies the analysis somewhat but is not required to establish any of the results. In fact, in earlier drafts, the nonstrategic demand was derived in a mean-variance optimization framework and the basic conclusions of the analysis remained the same. 
that is, $v_{-i}$ represents the value of a share of the firm's stock under monitoring vector $\tilde{\mathbf{m}}$, given that all strategic investors other than investor $i$ follow $\tilde{\mathbf{m}}$ and $i$ does not monitor. Let $\pi_{i}^{*}=\mathrm{P}\left[\tilde{m}_{i}^{*}=1\right]$ be the equilibrium probability that investor $i$ monitors.

The first two results, Lemmas 1 and 2, characterize equilibrium bid-ask prices as functions of (a) the correlation between informed demand, $D$, and monitoring activity, and (b) the equilibrium level of uninformed trade relative to informed trade.

Lemma 1. The equilibrium ask price satisfies

$$
p_{A}^{*}=1-\left(1-v^{*}\right) \frac{\mathrm{E}\left[\tilde{D}_{B}^{*} \mid \tilde{I}_{M}^{*}=0\right]+L_{B}}{\mathrm{E}\left[\tilde{D}_{B}^{*}\right]+L_{B}} .
$$

Proof. Consider any equilibrium $e^{*}$. Multiply both sides of marketmaker breakeven condition for the ask market, (BEA), by the ask price, $p_{A}$; this multiplication yields

$$
\mathrm{E}\left[\left(p_{A} d_{B}^{*}(\tilde{\boldsymbol{\phi}})+p_{A} \tilde{\ell}_{B}(p)\right)\left(p_{A}-I_{M}^{*}\right)\right]=0 .
$$

By definition, dollar buy-side demand by strategic investors, $\tilde{D}_{B}^{*}$, is given by $p_{A} \tilde{d}_{B}^{*}$. The definition of liquidity investor given by (BSLD) implies that dollar demand from liquidity investors, $p_{A} \tilde{\ell}_{B}^{*}$, is given by $X_{B}$; thus, equation (1) can be reexpressed as

$$
\mathrm{E}\left[\left(\tilde{D}^{*}+\tilde{X}_{B}\right)\left(p_{A}-I_{M}^{*}\right)\right]=0 .
$$

Noting that, by definition, $L_{B}=\mathrm{E}\left[\tilde{X}_{B}\right]$, and noting that the liquidity investor demand parameter, $X_{B}$, is independent of the strategic investors' monitoring strategies, and using the covariance identity $\mathrm{E}[\tilde{Y} \tilde{Z}]=\mathrm{E}[\tilde{Y}] \mathrm{E}[\tilde{Z}]+\operatorname{COV}[\tilde{Z}, \tilde{Y}]$, we obtain

$$
\left(\mathrm{E}\left[\tilde{D}^{*}\right]+L_{B}\right)\left(p_{A}-\mathrm{E}\left[I_{M}^{*}\right]\right)+\operatorname{COV}\left[\tilde{I}_{M}^{*}, D_{B}^{*}\right]=0 .
$$

Because our zero-one normalization of firm value implies that the expected value of the firm, $\mathrm{E}\left[\tilde{I}_{M}^{*}\right]$, equals the equilibrium probability of monitoring, $v^{*}$, we can simplify (3) to obtain the following expression.

$$
p_{A}^{*}=v^{*}+\frac{\mathrm{COV}\left[\tilde{I}_{M}^{*}, D_{B}^{*}\right]}{\mathrm{E}\left[D_{B}^{*}\right]+L_{B}} .
$$


Technical Lemma 1 in Appendix 1 shows that

$$
\operatorname{COV}\left[\tilde{I}_{M}^{*}, D_{B}^{*}\right]=-\left(1-v^{*}\right) E\left[D_{B}^{*}-E\left[D_{B}^{*}\right] \mid \tilde{I}_{M}^{*}=0\right] .
$$

Thus, combining expressions (4) and (5) we obtain

$$
p_{A}^{*}=v^{*}+\left(1-v^{*}\right) \frac{E\left[E\left[D_{B}^{*}\right]-D_{B}^{*} \mid \tilde{I}_{M}^{*}=0\right]}{\mathrm{E}\left[D_{B}^{*}\right]+L_{B}} .
$$

Rearranging this expression yields the expression for the equilibrium ask price used in Lemma 1.

Lemma 2. The equilibrium bid price satisfies

$$
p_{B}^{*}=1-\left(1-v^{*}\right) \frac{\mathrm{E}\left[\tilde{d}_{S}^{*} \mid \tilde{I}_{M}^{*}=0\right]+l_{S}}{\mathrm{E}\left[\tilde{d}_{S}^{*}\right]+l_{S}} .
$$

Proof. The proof is virtually identical to the proof of Lemma 1.

The characterizations obtained in Lemmas 1 and 2 are generally both standard and fairly intuitive. For example, as the depth of the market increases to infinity, the bid and ask prices converge to $v^{*}$, the intrinsic value of the firm. As market depth (measured by liquidity volume) falls, spreads rise. Because the marketmaker is trading against more than one informed investor, the spreads need not converge to unity (bid price to 0 , ask price to 1 ) as uninformed investors exit the market. Insiders selling the firm's stock are never sure that other insiders are not monitoring. Thus, a selling investor may incur trading losses when another investor decides to monitor and thus increases firm value. However, as we will see, although spreads do not converge to unity as uninformed traders exit, they do become large enough to eliminate the incentive of informed investors to trade.

\subsection{Inevitability of stochastic monitoring}

Our first result in this section is that monitoring by strategic investors is stochastic. Without trading profits, it is not worthwhile for investors to incur the costs of monitoring. 
However, trading profits can be earned only if there is some uncertainty on the part of the market regarding the monitoring strategy followed by the investors. Thus, monitoring policies are of necessity stochastic.

Theorem 1. No equilibrium exists in which monitoring occurs with probability 1 or probability 0 . In all equilibria, strategic sell-side demand is positive when all investors have initial share endowments, and strategic buy-side demand is positive whenever all investors have positive liquid wealth.

Proof. Let $e^{*}=\left(\tilde{\phi}^{*}, \tilde{\mathbf{m}}^{*}, p^{*}\right)$ be a candidate equilibrium. If $\mathrm{P}\left[\tilde{I}_{M}^{*}=0\right]=1$, then firm value equals 0 and informed traders never buy. The marketmaker breakeven conditions (BEA and $\mathrm{BEB}$ ) thus implies that $p^{*}=(0,0)$. Because the stock is free, this, in turn, implies that, for all $i$ such that (i) $b_{i}^{o}>0$, it is optimal to use liquid wealth to buy the asset and subsequently monitor with probability 1 . For all $i$, such that (ii) $\phi_{i}^{o}>c$, it is also optimal to monitor. By assumption (ASS), either (i) or (ii) holds. This fact contradicts the assertion that monitoring does not occur in $e^{*}$.

Next, suppose that $\mathrm{P}\left[\tilde{I}_{M}^{*}=0\right]=1$. This implies that at least one investor, say investor 1 , is monitoring with probability 1 . The marketmaker breakeven conditions (BEA and BEB) implies that $p^{*}=(1,1)$. Because $p^{*}=(1,1)$, the payoff to investor $i=1$, from monitoring is $\phi_{o}^{1}+b_{o}-c$. The payoff to investor 1 selling all his shares and investing proceeds in the bond is larger than this and equal to $\phi_{o}^{1}+b_{o}^{1}$. Thus, monitoring cannot occur with positive probability in the equilibrium strategy vector defined by $e^{*}$. This contradiction establishes the result that no investor monitors with certainty. Thus, we have shown that in all equilibria, monitoring occurs with a probability between zero and one.

To see that positive buy-side must be submitted by strategic investors with liquid wealth, note that if positive demand is not submitted in the ask market, then order flow is uncorrelated with firm value. Lemma 1 shows that, in this case, $p_{A}^{*}=v^{*}<1$. Some 
investor is monitoring in equilibrium, say investor 1. Investor 1's payoff from monitoring and buying shares, $\left(1 / v^{*}\right) b_{1}^{o}+\phi_{1}^{o}-c$, exceeds her payoff from monitoring and not submitting demand, $b_{1}^{o}+\phi_{1}^{o}-c$. This fact contradicts no strategic buy-side demand being submitted in equilibrium.

Next we show that positive sell-side demand must be submitted by informed investors when informed investors all have stock endowments. Note that if there is no informed demand on the sell side, then Lemma 1 shows that $p_{B}^{*}=v^{*}$. Some investor, say investor 1 , is monitoring with a positive probability less than 1 . If investor 1 is not selling when she is not monitoring, then her payoff when she chooses not to monitor is is $v_{-1}^{*}<v^{*}=p_{B}^{*}$. Thus, investor 1 is better off selling her endowment. This contradiction establishes the desired result.

The next set of results characterizes trading profits. These results show that, ex ante, investors who monitor earn a competitive return on their monitoring activity: that is, the trading profits from buying into the firm and then monitoring are exactly offset, in expected value terms, by the additional costs that the investor incurs from active monitoring.

Define the net trading profit, TP, by

$$
\operatorname{TP}_{i}(\tilde{\boldsymbol{\phi}}, \tilde{\mathbf{m}}, p)=b_{i}^{o}\left(1 / p_{A}-1\right)+\phi_{i}^{o}\left(1-\max \left[p_{B}, v_{-i}(\tilde{\mathbf{m}})\right]\right) .
$$

TP represents the total excess profit the investor can earn from monitoring and buying as opposed to not monitoring the firm. The first term on the right-hand side of equation (TP) used to define TP represents the profit from investing additional funds in the firm shares. Because monitoring increases the value of the firm's shares to $\$ 1.00$ and it costs $p_{A}$ to buy a share of the firm's stock from the marketmaker, the return on investing new funds in the firm and then monitoring is $1 / p_{A}-1$. This return multiplied by the firm's initial wealth balance, $b_{i}^{o}$, gives $b_{i}^{o}\left(1 / p_{A}-1\right)$, the profit from investing additional funds in 
the firm shares. The second term on the right-hand side of (TP) represents the net gain in value of the firm's initial endowment from monitoring. The value of each share is $\$ 1.00$ if the investor decides to monitor. If she decides not to monitor, the investor can either hold on to her shares and rely on the monitoring activities of other investors, thereby receiving $v_{-i}(\tilde{\mathbf{m}})$, or sell her shares to the marketmaker and receive $p_{B}$. The net gain, per initial share, from monitoring is thus $1-\max \left[p_{B}, v_{-i}(\tilde{\mathbf{m}})\right]$. The total net value increase on the initial holding is thus $\phi_{i}^{o}\left(1-\max \left[p_{B}, v_{-i}(\tilde{\mathbf{m}})\right]\right)$. Summing the two terms on the right-hand side of equation (TP) thus provides the trading profit to the investor from following activist policies. The next result characterizes this level of trading profits.

Lemma 3. In all equilibria $e^{*}$, the maximum gross trading profit from strategic investing equals the additional associated monitoring costs, that is,

$$
\max _{i \in \mathcal{K}} \operatorname{TP}_{i}\left(\tilde{\boldsymbol{\phi}}^{*}, \tilde{\mathbf{m}}^{*}, p^{*}\right)=c .
$$

Proof. If an investor decides to monitor, then her payoff is always highest if she invests all of her wealth in the firm. To understand this, note that the value of a share conditional on monitoring is $\$ 1.00$. The equilibrium ask price is $p_{A}^{*}<1$, as can be seen from Theorem 1 and Lemma 1. Thus, the investor's payoff from monitoring is

$$
\bar{\phi}-c=\left(\phi_{i}^{o}+b_{i}^{o} / p_{A}^{*}\right)-c .
$$

If an investor decides not to monitor, then it will never be optimal for her to increase her holdings. This follows because, given adverse selection, the equilibrium ask price for the firm's shares always exceeds the expected payoff from the shares given the equilibrium monitoring distribution. Thus, a fortiori, the price is higher than the price conditioned on $i$ 's not monitoring. Thus, if the investor does not monitor, she will either retain her initial position or sell out, depending on whether the payoff from selling out, $b_{i}^{o}+p_{B}^{*} \phi_{i}^{o}$, or the payoff from retaining the position, $b_{i}^{o}+\phi_{i}^{o} v_{-i}^{*}$, is higher. Thus, the payoff from not 
monitoring is

$$
b_{i}^{o}+\phi_{i}^{o} \max \left[p_{B}^{*}, v_{-i}^{*}\right] .
$$

This implies that investor $i$ will be indifferent to monitoring if and only if $\operatorname{TP}_{i}=c$. At least one investor must be indifferent to monitoring if the monitoring probability is to lie in $(0,1)$, which, by Lemma 1 , it must in any equilibrium. In contrast, if for some $i, \mathrm{TP}_{i}>c$, then $i$ will monitor with probability 1 , again contradicting Lemma 1 . Thus, we must have $\max _{i \in \mathcal{K}} \mathrm{TP}_{i}^{*}=c$.

Lemma 3 shows that, net of trading costs, strategic investors earn a fair rate of return on their monitoring activity; their abnormally positive portfolio returns are offset by the excess costs associated with monitoring.

\subsection{Heterogeneity in monitoring: Fringe versus core monitors}

The above results, although straightforward, have some interesting implications for the distribution of monitoring across strategic investors. To elucidate these implications, we first require a few definitions. For a given equilibrium, we represent the fraction of total expected strategic selling activity generated by strategic investor $i$ by $\eta^{i}$. More formally, for a given equilibrium $e^{*}$, let

$$
\eta_{i}^{*}=\frac{\phi_{i}^{o} \mathrm{P}\left\{\tilde{\phi}_{i}^{*}=0\right\}}{\sum_{j} \phi_{j}^{o} \mathrm{P}\left\{\tilde{\phi}_{j}^{*}=0\right\}} .
$$

Let $R^{*}=l_{S} / \mathrm{E}\left[\tilde{d}_{S}^{*}\right]$ represent market depth, the ratio of uninformed to informed sell-side demand in equilibrium $e^{*}$; let $\pi_{i}^{*}$ represent the probability that strategic investor $i$ monitors in equilibrium $e^{*}$. We say that strategic investor $i$ is a core monitor in $e^{*}$ if

$$
\frac{1}{1-\pi_{i}^{*}}>\frac{R^{*}+\sum_{j} \eta_{j}\left(\frac{1}{1-\pi_{j}^{*}}\right)}{R^{*}+1} .
$$

If the inequality in $(\mathrm{CR})$ is reversed and $\pi_{i}^{*}>0$, we will call investor $i$ a fringe monitor in $e^{*}$. For a given equilibrium, core monitors are those investors whose propensity to monitor is high relative to the weighted-average propensity. 
Note that the left-hand side of $(\mathrm{CR})$ always exceeds 1 . As the market becomes deeper, that is, when $R^{*} \rightarrow \infty$, the right-hand side of (CR) converges to 1 . Thus, as market depth increases without bound, all investors who monitor become core monitors. Further, because $R^{*}>0$, and because the fraction on the right-hand side of $(\mathrm{CR})$ is decreasing in $R^{*}$,

$$
\frac{R^{*}+\sum_{j} \eta_{j}\left(\frac{1}{1-\pi_{j}^{*}}\right)}{R^{*}+1}<\sum_{j} \eta_{j}\left(\frac{1}{1-\pi_{j}^{*}}\right) .
$$

Thus, if any investor monitors more than the weighted average of all investors, that is, if

$$
\frac{1}{1-\pi_{i}^{*}} \geq \sum_{j} \eta_{j}\left(\frac{1}{1-\pi_{j}^{*}}\right)
$$

then that investor is always a core monitor. Because the weights, $\left\{\eta_{j}\right\}$, sum to 1 , this last observation implies that some of the investors who monitor with positive probability are core monitors, and moreover that, if all strategic investors monitor with equal probability, all strategic investors are core monitors. It also shows that core monitors tend to engage in more monitoring than fringe monitors. These observations are formalized as follows.

Theorem 2. In equilibrium, investors never choose to decrease their holdings when they monitor. In fact, whenever their liquid wealth is positive, investors always increase their holdings when they choose to monitor. When they do not choose to monitor, investors either sell or retain their initial holdings. Moreover, core monitors sell initial holdings when they do not monitor, whereas fringe monitors retain their initial endowments.

Proof. If an investor decides to monitor, then her payoff is always highest if she invests all of her wealth in the firm. To see this, note that the value of a share conditional on monitoring is $\$ 1.00$. The ask price is less than $\$ 1.00$. On the other hand, the bid price is less than the expected payoff conditioned on the ex ante expected level of monitoring and, a fortiori, less than the value of the share conditioned on a given investor's increasing her probability of monitoring to 1 . Thus, a strategic investor faces losses from selling if she 
monitors. This implies that investing all liquid wealth in the firm maximizes a strategic investor's wealth if she monitors.

If a strategic investor does not monitor, then, because ask prices reflect the average level of monitoring (see Lemmas 1 and 2) and the actual level of monitoring conditioned on the investor's not monitoring is smaller, buying shares results in expected losses and will never be optimal. If investor $i$ holds and does not monitor, her payoff will equal her initial holding times the value of the share under the policy of not monitoring:

$$
\phi_{i}^{o} v_{-i}^{*} \text {. }
$$

If investor $i$ does not monitor and sells her stake, her payoff will be

$$
\phi_{i}^{o} p_{B}^{*} .
$$

Thus, the difference in the payoffs from selling (S) and not selling (NS) has the same sign as

$$
\left(1-\pi_{i}^{*}\right)-\frac{l_{S}+\mathrm{E}\left[\tilde{d}_{S}^{*}\right]}{l_{S}+\mathrm{E}\left[\tilde{d}_{S}^{*} \mid \tilde{I}_{M}^{*}=0\right]} .
$$

Next, note that, for each $j$,

$$
\mathrm{E}\left[{\tilde{d_{S j}^{*}}}_{j}\right]=\phi_{j}^{o} \mathrm{P}\left[\tilde{\phi}_{j}^{*}=0\right]
$$

and

$$
\mathrm{E}\left[\tilde{d}_{S j}^{*} \mid I_{M}^{*}=0\right]=\frac{\phi_{j}^{o} \mathrm{P}\left[\tilde{\phi}_{j}^{*}=0\right]}{1-\pi_{j}^{*}} .
$$

The second equality follows because monitoring decisions of strategic investors are independent in any Nash equilibrium and because the investors only submit sell-side demand when they no not monitor. Rearranging the above expression shows that (MON) has the same sign as the difference between the left and right-hand-side expressions used in the definition of a core monitor (CR). 
The logic behind Theorem 2 is that because, by monitoring, strategic investors ensure positive performance outcomes, they always want to increase their holdings when they monitor. The situation is somewhat different when a strategic investor decides not to monitor. Because other strategic investors may decide to monitor, not monitoring does not ensure adverse performance outcomes. If the likelihood that a given investor will monitor is low, this investor's failure to monitor may not lower the likelihood of successful monitoring sufficiently to support profitable selling, given the spread that must be paid to the marketmaker. Only investors whose failure to monitor is "very surprising" can profit from selling out when the market for the firm's shares is thin and bid-ask spreads are large. Core monitors are more likely to monitor ex ante, as shown by Theorem 2, and thus their failure to monitor is most surprising. These observations are illustrated by the following example.

Example. One core monitor and two fringe monitors. Suppose that there are four strategic investors. Bond endowments equal 0 for all strategic investors. Shareholdings, $\phi^{o}$, are given by the following table.

\begin{tabular}{cccc} 
Investor & $\phi^{o}$ & Investor & $\phi^{\circ}$ \\
\hline 1 & $1 / 2$ & 2 & $227 / 386$ \\
3 & $227 / 336$ & 4 & $43 / 64$ \\
\hline
\end{tabular}

Note that $0.50=\phi_{1}^{o}<\ldots<\phi_{4}^{o} \approx 0.70$. The cost of monitoring management, $c$, is $1 / 3$. Expected sell-side share demand from liquidity traders, $l_{S}$, is $1 / 4$ of a share. It is easy to verify that the following strategies constitute an equilibrium: investor 1: monitor and retain shareholding with probability 99/227, do not monitor and sell out with probability 128/227; investor 2 : monitor with probability $1 / 8$ and never trade; investor $3:$ monitor with probability 1/24 and never trade; investor 4: never monitor, never trade; marketmaker: set an ask price of $359 / 681$ and a bid price of $1 / 3$.

Which strategic investors are likely to be core monitors? Clearly, strategic investors must have holdings sufficient to justify incurring the fixed costs of monitoring. Thus, in- 
vestors with very little liquid wealth and small holdings of the firm's stock are unlikely to monitor. However, this does not imply that there is a monotonic relationship between the probability of monitoring and the size of shareholding. In fact, this conjecture is refuted by the previous example. In the example, the core monitor, investor 1 , had the smallest shareholding of the investors who monitored the firm in equilibrium (investors 1, 2, and 3). As the next result shows, the previous example is not exceptional in this regard. Rather, it is paradigmatic.

Lemma 4. No fringe monitor has strictly smaller endowments than any core monitor; that is, in equilibrium $e^{*}$, if strategic investor $i$ is a core monitor, then whenever $j$ is another strategic investor and

$$
\left(b_{j}^{o}, \phi_{j}^{o}\right) \supsetneqq\left(b_{i}^{o}, \phi_{i}^{o}\right),
$$

investor $j$ is not a fringe monitor.

Proof. Theorem 2 implies that, because investor $i$ is a core monitor, her optimal trading/monitoring strategy is to sell when she does not monitor. This implies that her trading profit is given by

$$
\mathrm{TP}_{i}^{*}=\left(1 / p_{A}^{*}-1\right) b_{i}^{o}+\left(1-p_{B}^{*}\right) \phi_{i}^{o}=c .
$$

If $\left(b_{j}^{o}, \phi_{j}^{o}\right) \supsetneqq\left(b_{i}^{o}, \phi_{i}^{o}\right)$, then

$$
\left(1 / p_{A}^{*}-1\right) b_{j}^{o}+\left(1-p_{B}^{*}\right) \phi_{j}^{o}<\left(1 / p_{A}^{*}-1\right) b_{i}^{o}+\left(1-p_{B}^{*}\right) \phi_{i}^{o} .
$$

Equations (6) and (7) imply that

$$
\left(1 / p_{A}^{*}-1\right) b_{j}^{o}+\left(1-p_{B}^{*}\right) \phi_{j}^{o}<c .
$$

By the definition of the trading profit function,

$$
\mathrm{TP}_{j}^{*} \leq\left(1 / p_{A}^{*}-1\right) b_{j}^{o}+\left(1-p_{B}^{*}\right) \phi_{j}^{o} .
$$


Thus, $\mathrm{TP}_{j}^{*}<c$. This implies that monitoring is not a best response for investor $j$, contradicting investor $j$ being a fringe monitor.

Lemma 5. Consider fringe monitors with positive stock endowments. For these investors, monitoring intensity is inversely related to the magnitude of their endowments. That is, if two fringe monitors have the same endowment of bonds, the fringe monitor with the larger stock endowment will monitor less. Similarly, if two fringe monitors have the same endowment of stocks, the fringe monitor with the larger bond endowment will monitor less.

Proof. If $i$ and $j$ are two fringe monitors with equal bond endowments, say, $b^{\prime}$ and $\phi_{i}^{o}>\phi_{j}^{o}$, it must be the case, by Lemma 3 and Theorem 2, that the ex ante trading profits of both investors are induced by strategies that involve holding initial endowments when not monitoring, and that the trading profits for both investors are the same. That is,

$$
\mathrm{TP}_{i}^{*}=\left(1 / p_{A}^{*}-1\right) b^{\prime}+\left(1-v_{-i}^{*}\right) \phi_{i}^{o}=c=\left(1 / p_{A}^{*}-1\right) b^{\prime}+\left(1-v_{-j}^{*}\right) \phi_{j}^{o}=\mathrm{TP}_{j}^{*} .
$$

Because $0>\phi_{i}^{o}>\phi_{j}^{o}$, the two extreme terms in the equality can be equal only if $1-v_{-i}^{*}<$ $1-v_{-j}^{*}$. Because $1-v^{*}=\left(1-v_{-i}^{*}\right)\left(1-\pi_{i}^{*}\right)=\left(1-v_{-j}^{*}\right)\left(1-\pi_{j}^{*}\right)$, this can be the case only if investor $i$ 's equilibrium probability of monitoring, $\pi_{i}^{*}$, is less than investor $j$ 's, $\pi_{j}^{*}$.

At an intuitive level, Lemma 5 holds for two reasons: (1) in equilibrium monitoring must be random and (2) random monitoring must be optimal for the randomizing investor. Suppose, counterfactually, that two investors, one "big" and one "small," are monitoring with the same probability. For condition (2) to be satisfied, the small investor's net trading profits would have to just equal the cost of monitoring. If this were the case, then because of the big investor's larger endowments, the big investor would strictly prefer monitoring. However, in this case, monitoring would be anticipated. Anticipation would lead to a revision of the marketmaker's quotes, which would eliminate monitoring profits. In order for the big investor to randomize, the big investor's incentives to monitor must be attenuated. The only factor that (a) varies between the investors, (b) is determined in equilibrium, and (c) 
affects incentives, is the value of firm when a particular investor withdraws from monitoring. Thus, to attenuate monitoring incentives for the big investor, the value of the firm without the monitoring of the big investor must increase. The only way to effect this increase is to increase the probability of monitoring by the small investor above the initially assumed level of equality. Thus, the small investor monitors more if she monitors at all.

\section{Monitoring by strategic investors who lack a toehold stake}

The analysis in Section 3 characterized general properties of the equilibrium behavior of agents. However, explicit comparative statics and formulae for equilibrium monitoring levels were not provided. To derive these types of results, we impose additional structure on the model. First, consider the case where strategic investors have no initial endowments of the security. This is an interesting special case of our analysis because the lack of a toehold in the firm eliminates any incentive for investors to monitor based on protecting their initial investment portfolio. Thus, the assumption mitigates against effective strategic monitoring. Nevertheless, it will be shown that, even in this case, strategic activism reduces agency costs. To make our analysis as straightforward as possible, we assume that all of the strategic investors have the same liquid asset balance, $B / N$, where $B$ is the total strategic wealth that can be invested in the firm. In this context, we address the issue of how variations in aggregate strategic wealth, $B$, uniformed investor demand, $L_{B}$, monitoring costs, $c$, and the dispersion of monitor wealth, $N$, affect the magnitude of the corporate agency problem and the microstructure of the security markets.

Under these assumptions, there is a unique symmetric equilibrium with each choice of exogenous model parameters: liquidity trader demand, strategic investor wealth endowments, monitoring costs, and dispersion of strategic wealth. This makes comparative static analysis fairly straightforward. The analysis is also simplified by our assumption that strategic investors have no initial endowments. This implies that marketmakers in the bid market for the firm's shares face only nonstrategic investor demand. Thus, the marketmaker 
breakeven condition for the bid market implies that bid market prices equal expected firm payoffs. This implies that the bid-ask spread is simply the difference between the ask price and the expected value of the firm's shares, $p_{A}-v$. The first result is a characterization of the symmetric Nash equilibrium. Also, we define the following functions:

$$
\begin{aligned}
f_{A}^{N}(v) & \stackrel{\text { def }}{=} 1-(1-v)\left(\frac{L_{B}}{B \pi(v, N)+L_{B}}\right), \\
\pi(v, N) & \stackrel{\text { def }}{=} 1-\sqrt[N]{1-v}
\end{aligned}
$$

Theorem 3. There exists a unique symmetric Nash equilibrium that is characterized as follows:

a. The equilibrium probability that a strategic investor will monitor and invest all her wealth in the firm's stock is given by $\pi\left(v^{*}, N\right)$, where $v^{*}$ is the unique solution to the equation $f_{A}^{N}(v)=B /(B+N C)$; the equilibrium probability that a strategic investor will not trade and will not monitor is $1-\pi\left(v^{*}, N\right)$.

b. The equilibrium ask price, $p_{A}^{*}$, equals $f_{A}^{N}\left(v^{*}\right)$; the equilibrium bid price, $p_{B}^{*}$, equals $v^{*}$.

Proof. See Appendix 1.

Theorem 3 permits a simple characterization of comparative statics. This characterization is provided by the next result.

Lemma 6. Under the assumptions of Theorem 3, the following comparative statics hold for the unique, symmetric Nash equilibrium:

a. Increasing liquidity investor buy-side demand, $L_{B}$, always increases firm value, $v^{*}$, and reduces bid-ask spreads, $p_{A}^{*}-v^{*}$.

$b$. Increasing aggregate strategic wealth, $B$, always increases firm value, $v^{*}$, and increases bid-ask spreads, $p_{A}^{*}-v^{*}$. 
c. Increasing monitoring costs, $c$, always lowers firm value, $v^{*}$, and has an indeterminate effect on the bid-ask spread.

d. Increasing the dispersion of strategic share holdings, $N$, lowers firm value, $v^{*}$. The effect of dispersion on bid-ask spreads, $p_{A}^{*}-v^{*}$, is not uniform. In deep markets, dispersion increases bid-ask spreads, whereas it reduces spreads in thin markets.

\section{Proof. See Appendix 1.}

Given the extant literature on financial markets, some of the comparative statics obtained in Lemma 6 are not surprising, such as increased liquidity-trader demand lowering bid-ask spreads. However, it is worth noting that increased dispersion of strategic-investor wealth, which might be expected to lower spreads by engendering competition between informed investors (e.g., Holden and Subrahmanyam, 1994), may increase spreads. This follows because increased dispersion of strategic ownership lowers the efficacy of strategic monitoring, which increases uncertainty regarding firm prospects. This effect may increase the trading profits that strategic investors earn and thus increase spreads.

\section{Monitoring by current strategic owners}

In Section 4, strategic investors had no initial share endowments. Now consider the opposite case, when the wealth of strategic investors consists entirely of an initial endowment of the firm's stock. This case is closer in spirit to most of the extant research on investor activism because monitoring is motivated by a desire to protect the investor's initial ownership position in the firm. More specifically, assume that each strategic investor is endowed with $\Phi / N$ shares of the firm's stock. As in Section 4 , the analysis will delineate how variation in key exogenous parameters - aggregate strategic investor ownership, $\Phi$, uninformed investor demand, and the dispersion of strategic ownership - affects the magnitude of the corporate agency problem and the microstructure of the security market. Some of the results in this section are quite similar to the results obtained previously. We will abbreviate the discussion 
and proofs of these results, and instead concentrate on the results that emerge from the new assumptions regarding the composition of the initial endowment of strategic investors.

Because the effects of endogenous uninformed demand are virtually identical in the current scenario to those obtained in the previous scenario, in this section we consider only the case of nonstrategic investors who submit fixed demands: the liquidity investors scenario. Our first result is a characterization of the symmetric Nash equilibrium. Define

$$
\begin{aligned}
& f_{B}^{N}(v) \stackrel{\text { def }}{=} 1-(1-v)\left(\frac{\Phi+l_{S}}{\Phi(1-\pi(v, N))+l_{S}}\right), \\
& \pi(v, N) \stackrel{\text { def }}{=} 1-\sqrt[N]{1-v} .
\end{aligned}
$$

Theorem 4. A unique symmetric Nash equilibrium exists and is characterized as follows:

a. The equilibrium probability that a strategic investor will retain her holdings and monitor is $\pi\left(v^{*}, N\right)$, where $v^{*}$ is the unique solution to the equation $f_{B}^{N}(v)=(\Phi-N C) / \Phi$; the equilibrium probability that a strategic investor will sell out and not monitor is $1-\pi\left(v^{*}, N\right)$.

b. The equilibrium bid price, $p_{B}^{*}$, equals $f_{B}^{N}\left(v^{*}\right)$; the equilibrium ask price, $p_{A}^{*}$, equals $v^{*}$.

Proof. See Appendix 1.

Lemma 7. Under the assumptions of Theorem 4, the following comparative statics hold for the unique symmetric Nash equilibrium.

a. Increasing liquidity investor sell-side demand, $l_{S}$, always lowers firm value, $v^{*}$, and reduces bid-ask spreads, $p_{A}^{*}-v^{*}$.

$b$. Increasing strategic investor endowments, $\Phi$, always increases firm value, $v^{*}$, and has an indeterminate effect on the bid-ask spread.

c. Increasing monitoring costs, $c$, always lowers $v^{*}$. The effect of changes in $c$ on the 
bid-ask spread is indeterminate.

d. Increasing the dispersion of strategic share holdings, $N$, lowers $v^{*}$. The effect of dispersion on bid-ask spreads is not uniform. In deep markets, dispersion increases bid-ask spreads whereas it reduces spreads in thin markets.

Proof. See Appendix 1.

This result shows that liquidity in bid markets has an adverse effect on monitoring, in contrast to the positive effect derived previously for the ask market. Thus, the overall effect of increased liquidity is subtle. This result is consistent with recent literature on monitoring, notably, Kahn and Winton (1998) and Maug (1998), that have identified tradeoffs associated with increasing market liquidity. The lemma also shows that increasing strategic shareholder endowments increases firm value because capital gains on endowments increase the incentive of informed traders to monitor above and beyond the levels sustainable purely by trading profits. This result is also consistent with the extant literature. For example, in a somewhat different context featuring exogenous private information, Khanna and Sonti (1999) develop a model in which capital gains on existing shares can induce a pattern of trade that increases firm value and which could not be sustained by trading profits alone.

The most surprising comparative static obtained in this section is the relationship between strategic investor share ownership and the magnitude of bid-ask spreads. As shown by Figure 1, the relationship is not, in general, monotonic. Increasing strategic ownership increases informed trading, which initially increases spreads. However, as strategic ownership endowments increase, the potential profits of informed trade fall, relative to the costs engendered by monitoring uncertainty. This leads strategic investors to follow predictable policies that feature a high degree of monitoring when their initial endowments become very large. Thus, as strategic (informed) ownership increases, the volume of informed trade may 


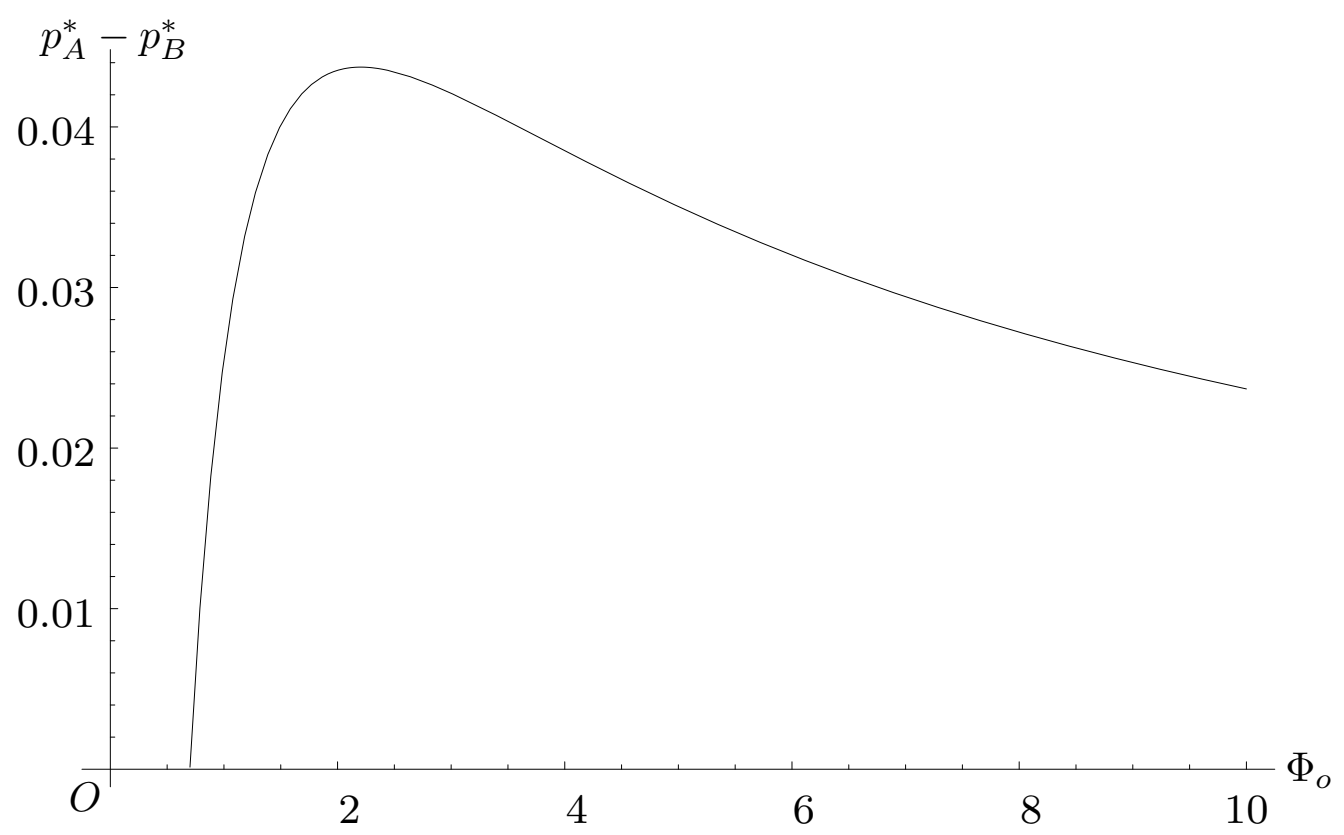

Figure 1. Increasing informed strategic demand reduces bid-ask spreads. The fixed parameters for this example are as follows: $N=7, l_{S}=8.00, C=0.10$. The total holdings of strategic investors $(\Phi)$, plotted on the horizontal axis, vary from 0.70 to 10 shares. The equilibrium bid-ask spread $p_{A}^{*}-p_{B}^{*}$ is plotted on the vertical axis.

actually fall. This effect eventually lowers bid-ask spreads.

\section{Extensions}

\subsection{Microstructure: Model of order flow}

Our model of financial market structure follows a simplified version of the Admati and Pfleiderer (1989) and Easley and O'Hara (1992) approach by assuming that marketmakers post a single price at which they will meet demand. The advantage of utilizing this framework for our analysis is that it simplifies the analysis enormously and allows us to develop simple formulae linking trade intensity to share endowments and investor activism (for example, equation (CR)). Microstructure models such as Kyle (1985) and Glosten and Milgrom (1985) permit marketmakers to observe the order flow before filling market orders. In Kyle the marketmaker observes only aggregate order flow, whereas in Glosten and Mil- 
grom, the marketmaker observes individual orders. In either case, the marketmaker's price varies with the order flow. One technical complication introduced by conditional order flow is that formulae must be developed for updating the marketmaker's prior beliefs. In most microstructure research, three conditions are essential for developing this updating rule: normally distributed demand vectors for noise traders, exogenous signals that are normally distributed, and linear strategies played by informed traders. These assumptions ensure that demand vectors are normally distributed and this allows for the use of simple updating rules. However, in our setting uncertainty is endogenous rather than exogenous. Because of the fixed costs of monitoring, optimal strategies will never place any weight on monitoring conjoined with small buy orders (such orders cannot recover the costs of monitoring). Because all uncertainty is generated endogenously in our model, this implies that the conditional distribution of trade conditioned on monitoring will have limited and asymmetric support, and thus not be Normal. Therefore, simple, linear, updating rules cannot be developed to model the marketmaker's pricing function. This fact makes developing a tractable, conditional-quote model of great generality somewhat challenging in our setting.

We claim that our most surprising result, that monitoring is not, in general, monopolized by the largest traders (the investors holding the most shares of the firm's stock), extends to the conditional quote setting. The intuition behind this assertion is as follows: In our fixed-quote analysis, if the probability of monitoring for the small investor is less than that for the large investor, a large investor has more to lose by not monitoring and relying on the monitoring efforts of a small investor. This fact allows the market to predict that the large investor will try to monitor. However, predictability eliminates the surprise required for profitable trading. Since trading profits are necessary to support monitoring activity, this contradicts the existence of equilibria in which monitoring activity was shared between investors, with the larger investor carrying the greater burden.

With conditional quotes, a new effect is introduced: The investor with the highest 
expected buying intensity expects her buy order to be filled at the lowest prices. At first sight, this observation seems paradoxical but it is fairly obvious upon reflection. Consider a simple example: two investors, one expected to buy with certainty and the other expected to sell with certainty. The expected buyer believes that her buy orders will be the only buy orders placed. Thus, her orders will be filled after the marketmaker observes one buy order. The investor expected to sell believes that if, instead of selling, she decides to buy, her buy order will be one of two buy orders placed and thus will be filled by the marketmaker at a higher price than that conjectured by the investor that is expected to buy.

Investors with the highest monitoring intensity have the highest buying intensity. Thus, with conditional quotes, they expect lower quotes conditional on monitoring and buying than investors monitoring with less intensity. For this reason these investors find the trading profits higher for buying and monitoring. If these high-intensity monitoring investors also have larger holdings, then they also have more to gain, in terms of the intrinsic value of their holdings, from monitoring. However, together these two effects allow the marketmaker to correctly predict that they will monitor. This predictability eliminates trading profits and thus eliminates the surprise factor required for profitable monitoring. In short, conditional quotes strengthen, rather than attenuate, the incentives for multiple investor monitoring outlined in the previous sections of the paper. ${ }^{7}$

\subsection{Microstructure: Model of nonstrategic investor behavior}

In this article we assume that the actions of liquidity traders are exogenous. This raises the issue of the robustness of our results to endogenous liquidity trader demand. Demand on the part of nonstrategic traders can be endogenized by assuming either time preferences

7 Readers interested in inspecting an equilibrium featuring the properties asserted in this paragraph may read "Addendum to Investor Activism and Financial Market Structure," a file available at http://freeman.tulane.edu/faculty/tnoe.htm. Note that, because the conditional expected value of the firm has to be computed for each pattern of order flow in the conditional quote model, tractability requires that we restrict the order size to a few discrete values. A restriction we did not have to impose in this paper. 
(liquidity) or risk aversion (hedging) on the part of nonstrategic traders. A number of authors have used one or both of these assumptions; see, for example, Dow and Gorton (1995). In an earlier draft of this paper we endogenized liquidity trade via the assumption of risk aversion on the part of nonstrategic traders. However, with endogenous demand, in contrast to the exogenous nonstrategic trader behavior modeled herein, the intensity of trade by nonstrategic traders will vary with the degree of adverse selection in the securities markets. The higher the adverse selection losses, the lower the level of uninformed demand. This contingency makes "market breakdown" possible. The market breaks down when high spreads drive nonstrategic traders out of the market. The exit of nonstrategic traders eliminates the trading profits and thus the incentive for strategic investors to trade. Other than introducing the possibility of market breakdown, endogenizing nonstrategic trade does not have an appreciable qualitative impact on our analysis. Moreover, the possibility of market breakdown strengthens rather than weakens our results on the viability of monitoring by investors other than the largest investor. Ownership dispersion and a multiplicity of monitoring investors may be necessary conditions for monitoring. As we showed in Lemma 6, increasing ownership dispersion can lower bid-ask spreads in thin markets. With endogenous nonstrategic demand, market exit by nonstrategic investors may lead to market breakdown if ownership is concentrated. Without the profits from market trading, monitoring may not be worthwhile. In these cases, some dispersion of ownership and monitoring activity is required if monitoring is to occur at all.

\subsection{Penalties for detected opportunistic behavior by managers}

In this article we assume that managers face no penalty from failed attempts to consume perks. This implies that perk consumption always occurs in the absence of monitoring. Managers can never be deterred by the mere threat of monitoring. The introduction of a penalty for managers caught consuming perks would probably more accurately reflect the stylized facts regarding managerial labor markets. However, it would complicate the anal- 
ysis without qualitatively reversing any of the results. The only significant impact on our earlier results would be that shifts in exogenous parameters would affect management's behavior as well as external monitoring levels. In our analysis, the impact of parameter shifts is only on monitoring, that is, changing market-structure variables increases or lowers monitoring activity by investors. In the presence of costs for failed attempts at perk consumption, changes in market-structure parameters would induce strategic managers to change perk consumption behavior to compensate for shifts in the cost/benefit ratio of monitoring. Thus, managers would raise their probability of consuming perks when the costs of monitoring rise, and lower their probability of consuming perks when the costs of monitoring fall. This shift in managerial behavior would offset, to some extent, the direct effects of exogenous parameter shifts on the costs and benefits of monitoring and thus muffle the effect of exogenous parameter shifts on monitoring probabilities. Therefore, with an internal governance system, some of the impact of market-structure parameter shifts will be reflected in changes in managerial behavior rather than in changes in monitoring probabilities.

\subsection{Strategic investors: Deliberate randomization versus random monitoring costs}

Previously in this article, we showed that surprise is necessary for strategic investors to capture trading profits from monitoring. In our analysis, surprise necessitates the playing of random strategies by strategic investors. Explicit randomization by strategic investors may seem implausible intuitively. However, our results can be interpreted in another way. As Harsanyi (1973) has shown, equilibria involving random strategies can be replicated by games in which all agents play deterministic strategies but have private information about a small perturbation of their payoff function. In our setting, the most natural private information parameter is the cost of monitoring. Thus, an alternative interpretation of our results is that the costs of monitoring for strategic investor $i$ are given by $c+\tilde{\epsilon}_{i}$. Strategic investor $i$ will monitor when she has a relatively low draw of $\epsilon_{i}$ and not monitor (either selling or not trading at all) when her draw is relatively high. Because the marketmaker 
and the other investors do not know $\tilde{\epsilon}_{i}$, they will frame their strategies based on averaging across all possible realizations of the perturbation parameter. Under the assumption that $\epsilon_{i} \approx 0$ for all strategic investors, the strategies in this perturbed game approximate, to an arbitrary degree of accuracy, those in the game we analyze in this article. Thus, our model is consistent with unpredictability in monitoring activity caused by small variations in the costs of monitoring faced by strategic investors rather than by explicit randomization.

\subsection{Strategic investors: Portfolio allocation}

In this article, we allow for many activist investors, but allow only one firm to be a target for activism. It is difficult to see how allowing for multiple target firms for strategic monitoring would challenge any of the results in this article; however, allowing for multiple target firms as well as multiple strategic investors would enable us to address issues that we are unable to address within the current framework. As shown previously, in our analysis strategic investors are ill-matched with the firms they own. In the model developed in this article, these investors adopt a passive, no-trade strategy. With a larger menu of investment options, such strategic investors might be attracted to firms with less strategic investor interest and/or lower monitoring costs. The potential thus exists for developing a theory to explain the security demands of strategic investors in terms of governance, internal control, and firm-specific market structure variables. Investors could also increase their ability to profit via surprise intervention by identifying multiple potential targets. In the current analysis, surprise is induced by uncertainty about whether the investor is on the buy or the sell side of an individual firm. Increased targeting flexibility could relax the upper bound on profits imposed by trading in the shares of a single firm.

\section{Conclusions}

We have considered the role of financial market structure and strategic investors in the corporate governance process. The analysis shows that strategic investors can effectively and profitably monitor management even when monitoring is costly and such investors lack any 
initial stake in the firm. We analyzed the effect of a number of factors on strategic monitoring and market depth. These factors include the cost of monitoring, the initial premonitoring wealth and shareholdings of strategic investors, and the structure of nonstrategic investor demand. We performed our analysis within a framework that endogenized a number of different facets of corporate governance and financial markets. 
Appendix 1: Proofs of SElECTEd PRopositions

Technical Lemma 1. If $\tilde{X}$ is any integrable random variable and $\tilde{I}$ is any zero/one-valued random variable, then

$$
\operatorname{COV}[\tilde{X}, \tilde{I}]=-\mathrm{P}[\tilde{I}=0] E[(\tilde{X}-\mathrm{E} \tilde{X}) \mid \tilde{I}=0] .
$$

Proof. For the proof of this lemma only, let $\theta=\mathrm{P}[\tilde{I}=1]$. The properties of conditional expectations imply that

$$
\begin{aligned}
\operatorname{COV}[\tilde{X}, \tilde{I}] & =\mathrm{E}[(\tilde{I}-\mathrm{E} \tilde{I})(\tilde{X}-\mathrm{E} \tilde{X}) \mid \tilde{I}=0](1-\theta)+\mathrm{E}[(\tilde{I}-\mathrm{E} \tilde{I})(\tilde{X}-\mathrm{E} \tilde{X}) \mid \tilde{I}=1] \theta \\
& =-\theta(1-\theta) \mathrm{E}[(\tilde{X}-\mathrm{E} \tilde{X}) \mid \tilde{I}=0]+\theta(1-\theta) \mathrm{E}[(\tilde{X}-\mathrm{E} \tilde{X}) \mid \tilde{I}=1] \\
& =\theta(1-\theta)(\mathrm{E}[(\tilde{X}-\mathrm{E} \tilde{X}) \mid \tilde{I}=1]-\mathrm{E}[(\tilde{X}-\mathrm{E} \tilde{X}) \mid \tilde{I}=0]) .
\end{aligned}
$$

Now,

$$
0=\mathrm{E}[(\tilde{X}-\mathrm{E} \tilde{X})]=\theta \mathrm{E}[(\tilde{X}-\mathrm{E} \tilde{X}) \mid \tilde{I}=1]+(1-\theta) \mathrm{E}[(\tilde{X}-\mathrm{E} \tilde{X}) \mid \tilde{I}=0]
$$

Thus,

$$
\mathrm{E}[(\tilde{X}-\mathrm{E} \tilde{X}) \mid \tilde{I}=1]=-\frac{(1-\theta)}{\theta} \mathrm{E}[(\tilde{X}-\mathrm{E} \tilde{X}) \mid \tilde{I}=0] .
$$

Combining equations (A1.2) and (A1.4) yields the desired result.

Proof of Theorem 3. Because all endowments are symmetric by assumption, in any symmetric equilibrium investors follow the same strategies. As shown in Lemma 1, monitoring must occur with a probability between 0 and 1 in any Nash equilibrium. These two observations imply that all investors monitor with the same probability in any equilibrium. Symmetry then implies that the probability that any individual investor will monitor is given by the function $\pi(\cdot)$ defined just above the statement of Theorem 3. As shown in the proof of 
Lemma 3, investors endowed entirely with liquid wealth will always invest all their wealth in the firm when they monitor and will not invest any wealth in the firm when they refrain from monitoring. Thus, $\pi$ represents the probability that a strategic investor will monitor and use all her wealth to buy claims, and $1-\pi$ represents the probability that the investor will not buy claims and will not monitor. This implies that expected demand from strategic investors in dollar terms is given by $\pi B$. The properties of the covariance operator derived in Technical Lemma 1 imply that

$$
\operatorname{COV}\left[\tilde{D}_{A}, \tilde{I}_{M}\right]=(1-v) \mathrm{E}\left[\tilde{D}_{A}\right]
$$

Thus,

$$
\operatorname{COV}\left[\tilde{D}_{A}, \tilde{I}_{M}\right]=(1-v) B \pi
$$

The definition of the marketmaker's best response then implies that the ask price is given by $f_{A}^{N}(\cdot)$. For strategic investors to be willing to randomize the payoff from monitoring, given by $(B / N) / f_{A}^{N}-C$, and the payoff from not monitoring, given by $(B / N)$, must be equal. This implies that, in any symmetric equilibrium, it must be the case that $f_{A}^{N}(v)=B /(B+N C)$. The existence of a unique value of $v \in(0,1)$ satisfying this condition follows from the fact that $f_{A}^{N}$ is increasing and continuous over the interval $[0,1]$, with $f_{A}^{N}(0)=0$ and $f_{A}^{N}(1)=1$.

Proof of Lemma 6. By Theorem 3, in the unique symmetric equilibrium the following relationship holds:

$$
f_{A}^{N}(v)=B /(B+N C) .
$$

Manipulation of this equation yields the following expression:

$$
c=\Xi_{N}\left(v ; B, L_{B}\right) \stackrel{\text { def }}{=} \frac{L_{B} B(1-v)}{N\left(L_{B} v+B \pi(v, N)\right)} .
$$


For all values of the parameters $N, L_{B}$, and $B, \Xi_{N}$ is a continuous, strictly decreasing function of $v$ with $\lim _{v \rightarrow 0} \Xi_{N}=\infty$ and $\lim _{v \rightarrow 1} \Xi_{N}=0$.

Using equation (A1.8), we can simply establish all of the comparative static results given in the Lemma. First consider (a). Increasing liquidity, $L_{B}$, uniformly increases $\Xi$, thus, to maintain equality, $v$ must increase. Using the relationships defined in (A1.8) then yields the assertions of part (a) with the exception of the characterization of the bid-ask spread. This characterization follows from the equilibrium condition $f_{A}^{N}=B /(B+N C)$, which implies that the equilibrium spread, the difference between the ask price and expected firm value, is given by

$$
B /(B+N C)-v^{*} .
$$

Increasing $L_{B}$ increases $v^{*}$ and thus, from expression (A1.9), lowers the bid-ask spread.

Next, consider part (b). Note that $\Xi_{N}$ is uniformly strictly increasing in $B$. Thus, an increase in $v$ is required to offset any increase in $B$ to maintain equality in equation (A1.8). For the same reasons as those given in the proof of (a), this establishes the results in (b) except for the assertions regarding the effect of increases in $B$ on bid-ask spreads. Given that both terms in the difference expression defining the equilibrium spread expression (A1.9) increase when $B$ increases, a nonmonotonic relationship between spreads and value is plausible. The actual nonmonotonicity of the relationship follows from numerical examples, which available from the author on request.

Now consider part (c). An increase in $c$ requires a corresponding decrease in $v$ to maintain equality in equation (A1.8). Thus, increasing $c$ increases $v$. For the same reasons as those given in the proof of parts (a) and (b), this argument establishes the results in (c), except for the assertions regarding the effect of increases in $c$ on bid-ask spreads. Given that both terms in the difference expression defining the equilibrium spread, (A1.9), decrease when $c$ increases, a nonmonotonic relationship between spreads and value is plausi- 
ble. The actual nonmonotonicity of the relationship follows from numerical examples, which are available from the author on request.

Finally, consider (d). As a function of $N, \Xi_{N}$ is decreasing. This follows from the fact that

$$
N\left(L_{B}(1-z)+B \pi^{*}(v, N)\right)
$$

is strictly increasing. This assertion follows because the previous expression is equal to

$$
N\left(L_{B} v+B(1-\sqrt[N]{1-v})\right)
$$

and from the following fact: For any constant $y \in(0,1)$, the function

$$
N \rightarrow N(1-\sqrt[N]{1-y}) \text { is increasing. }
$$

Assertion (A1.12) follows, for instance, from the proof of Result 42 in Hardy, Littlewood, and Pólya (1952).

Let $\left(N^{\prime}, c, B, L_{B}\right)$ and $\left(N^{\prime \prime}, c, B, L_{B}\right)$ be two fixed sets of parameters, $N^{\prime \prime}>N^{\prime}$, and let $v^{* \prime}$ be implicitly defined by $c=\Xi_{N^{\prime}}\left(v^{* \prime}, B, L_{B}\right)$. Let $v^{* \prime \prime}$ be implicitly defined by $c=\Xi_{N^{\prime}}\left(v^{* \prime \prime}, B, L_{B}\right)$. Then, because $\Xi$ is decreasing in $N$,

$$
\Xi_{N^{\prime}}\left(v^{* \prime}\right)>\Xi_{N^{\prime \prime}}\left(v^{* \prime}\right) .
$$

Because, by definition, $c=\Xi_{N^{\prime}}\left(v^{* \prime}\right)$ and $c=\Xi_{N^{\prime \prime}}\left(v^{* \prime \prime}\right)$,

$$
\Xi_{N^{\prime}}\left(v^{* \prime}\right)=\Xi_{N^{\prime \prime}}\left(v^{* \prime \prime}\right) .
$$

Expressions (A1.13) and (A1.14) imply that $\Xi_{N^{\prime \prime}}\left(v^{* \prime \prime}\right)>\Xi_{N^{\prime \prime}}\left(v^{* \prime}\right)$. The fact that $\Xi_{N^{\prime \prime}}$ is decreasing then implies that $v^{* \prime \prime}<v^{* \prime}$. This implies that the equilibrium value of the firm under $N^{\prime}$, which is given by $v^{* \prime}$, is higher than the equilibrium value of the firm associated with $N^{\prime \prime}$, which is given by $v^{* \prime \prime}$. 
Proof of Theorem 4. This proof is virtually identical to the proof of Theorem 3. Thus, this proof will be omitted.

Proof of Lemma 7. This proof is virtually identical to the proof of Lemma 6. Thus, this proof will be omitted. 


\section{REFERENCES}

Admati, A., and P. Pfleiderer, 1989, Divide and conquer: A theory of intraday and day-ofthe-week mean effects, Review of Financial Studies 2, 189-223.

Admati, A., P. Pfleiderer, and J. Zechner, 1994, Large shareholder activism, risk-sharing, and financial market equilibrium, Journal of Political Economy 102, 1097-1130.

Bethel, J., J. Liebeskind, and T. Opler, 1998, Block share purchases and corporate performance, Journal of Finance 52, 605-634.

Burnhardt, D., and E. Hughson, 1997, Splitting orders, Review of Financial Studies 10, 69-101.

CalPERS, 1998, Why Corporate Governance Today?, position paper, available at the corporate governance net, http://www.corpgov.net.

Chernoff, J., and M. Star, 1993, Three studies support relationship investing, Pensions \& Investments $213-30$.

Cornelli, F., and D. Li, 1999, Risk Arbitrage in Takeovers, Working paper, London Business School.

Copeland, T. and D. Galai, 1983, Information effects and the bid-ask spread, Journal of Finance 38, 1457-1469.

Dow, J., and G. Gorton, 1995, Profitable informed trading in a simple general equilibrium model of asset pricing, Journal of Economic Theory 67, 327-369.

Easley, D. and M. O'Hara, 1992, Adverse selection and large trade volume: The implications for market efficiency, Journal of Financial and Quantitative Analysis, 27, 185-208.

Economist, 1997, In the boardroom: Kid's stuff, June 21, 66-67.

Gillan, S., 1995, Shareholder activism through the proxy mechanism: An empirical investigation, working paper, University of Texas.

Glosten, L., and P. Milgrom, 1985, Bid, ask and transaction prices in a specialist market with heterogeneously informed traders, Journal of Financial Economics 14, 71-100.

Hardy, G., J. Littlewood, and G. Pólya, 1952, Inequalities, Cambridge, UK, Cambridge University Press.

Harsanyi, J., 1973, Games with randomly distributed payoffs: A new rationale for mixedstrategy equilibrium points, International Journal of Game Theory 2, 1-23.

Hawley, J., and A. Williams, 1996, Corporate governance in the United States: The rise of fiduciary capitalism, working paper, St. Mary's College, Moraga, CA.

Holden, C., and A. Subrahmanyam, 1994, Risk aversion, imperfect competition, and longlived Information, Economics Letters 44, 181-190.

Kahn, C., and A. Winton, 1998, Ownership structure, speculation, and shareholder inter- 
vention, Journal of Finance 53, 99-129.

Khanna, N. and R. Sonti, 1999, Feedback effect of stock prices on fundamental values: Price manipulation and herding with rational expectations, working paper, Michigan State University.

Kini, O., and S. Mian, 1993, Bid-ask spreads and ownership structure, Journal of Financial Research 18, 401-414.

Kyle, A., 1985, Continuous auctions and insider trading, Econometrica 53, 1315-1335.

Maug, E., 1998, Large shareholders as monitors: Is there a tradeoff between liquidity and control?, Journal of Finance 53 - February, 65-98.

Opler, T., and J. Sokobin, 1995, Does co-ordinated institutional activism work? An analysis of the activities of the council of institutional investors, working paper, Ohio State University, Columbus, $\mathrm{OH}$.

Parino, R., R. Sias, and L. Starks, 2000, Voting with their feet: Institutional investors and CEO turnover, working paper, University of Texas.

Shleifer, A., and R. Vishny, 1986, Large shareholders and corporate control, Journal of Political Economy 98, 461-488.

Smith, M., 1996, Shareholder activism by institutional investors: Evidence from CalPERS, Journal of Finance 51, 227-252.

Spatt, C., 1988, Strategic analysis of takeover bids, in Financial Markets and Incomplete Information: Frontiers of Modern Financial Theory, S. Bhattacharya and G. Constantinides, eds., New York, Rowman \& Littlefield.

Strickland, D., K. Wiles, and M. Zenner, 1996, A requiem for the USA: Is small shareholder monitoring effective? Journal of Financial Economics 40, 319-338.

Winton, A., 1993, Limitation of liability and the ownership structure of the firm, Journal of Finance 48 487-512. 
Our papers can be downloaded at:

http://cerp.unito.it

CeRP Working Paper Series:

$N^{\circ} 1 / 00 \quad$ Guido Menzio

$\mathrm{N}^{\circ} 2 / 00 \quad$ Pier Marco Ferraresi Elsa Fornero

$\mathrm{N}^{\circ}$ 3/00 Emanuele Baldacci

Luca Inglese

$N^{\circ} 4 / 01 \quad$ Peter Diamond

$\mathrm{N}^{\circ} 5 / 01 \quad$ Vincenzo Andrietti

$\mathrm{N}^{\circ}$ 6/01 Flavia Coda Moscarola

$\mathrm{N}^{\circ} 7 / 01 \quad$ Margherita Borella

$N^{\circ} 8 / 01 \quad$ Margherita Borella

$\mathrm{N}^{\circ}$ 9/01 Hans Blommestein

$\mathrm{N}^{\circ}$ 10/01 Vincenzo Andrietti and Vincent Hildebrand

$\mathrm{N}^{\circ}$ 11/01 Mara Faccio and Ameziane Lasfer

$N^{\circ} 12 / 01 \quad$ Roberta Romano

$N^{\circ} 13 / 01 \quad$ Michela Scatigna

$\mathrm{N}^{\circ}$ 14/01 Thomas H. Noe
Opting Out of Social Security over the Life Cycle

Social Security Transition in Italy: Costs, Distorsions and (some) Possible Correction

Le caratteristiche socio economiche dei pensionati in Italia. Analisi della distribuzione dei redditi da pensione (only available in the Italian version)

Towards an Optimal Social Security Design

Occupational Pensions and Interfirm Job Mobility in the European Union. Evidence from the ECHP Survey

The Effects of Immigration Inflows on the Sustainability of the Italian Welfare State

The Error Structure of Earnings: an Analysis on Italian Longitudinal Data

Social Security Systems and the Distribution of Income: an Application to the Italian Case

Ageing, Pension Reform, and Financial Market Implications in the OECD Area

Pension Portability and Labour Mobility in the United States. New Evidence from the SIPP Data

Institutional Shareholders and Corporate Governance: The Case of UK Pension Funds

Less is More: Making Shareholder Activism a Valuable Mechanism of Corporate Governance

Institutional Investors, Corporate Governance and Pension Funds

Investor Activism and Financial Market Structure 